\title{
Seismic structure beneath the Gulf of Aqaba and adjacent areas based on the tomographic inversion of regional earthquake data
}

\author{
Sami El Khrepy ${ }^{1,2}$, Ivan Koulakov ${ }^{3,4}$, Nassir Al-Arifi ${ }^{1}$, and Alexey G. Petrunin ${ }^{5,6,7}$ \\ ${ }^{1}$ King Saud University, Riyadh, Saudi Arabia, P.O. Box 2455, Riyadh 11451, Saudi Arabia \\ ${ }^{2}$ National Research Institute of Astronomy and Geophysics, Seismology Department, NRIAG, 11421 Helwan, Egypt \\ ${ }^{3}$ Trofimuk Institute of Petroleum Geology and Geophysics SB RAS, Prospekt Koptyuga 630090, Novosibirsk, Russia \\ ${ }^{4}$ Novosibirsk State University, Novosibirsk, Russia \\ ${ }^{5}$ Goethe University, 60323 Frankfurt am Main, Germany \\ ${ }^{6}$ GeoForschungsZentrum Potsdam, Telegrafenberg, 14473 Potsdam, Germany \\ ${ }^{7}$ Schmidt Institute of Physics of the Earth, B. Gruzinskaya 10, Moscow, Russia
}

Correspondence to: Sami El Khrepy (k_sami11@yahoo.com) and Ivan Koulakov (ivan.science@gmail.com)

Received: 2 January 2016 - Published in Solid Earth Discuss.: 18 January 2016

Revised: 23 May 2016 - Accepted: 24 May 2016 - Published: 20 June 2016

\begin{abstract}
We present the first 3-D model of seismic $P$ and $S$ velocities in the crust and uppermost mantle beneath the Gulf of Aqaba and surrounding areas based on the results of passive travel time tomography. The tomographic inversion was performed based on travel time data from $\sim 9000$ regional earthquakes provided by the Egyptian National Seismological Network (ENSN), and this was complemented with data from the International Seismological Centre (ISC). The resulting $P$ and $S$ velocity patterns were generally consistent with each other at all depths. Beneath the northern part of the Red Sea, we observed a strong high-velocity anomaly with abrupt limits that coincide with the coastal lines. This finding may indicate the oceanic nature of the crust in the Red Sea, and it does not support the concept of gradual stretching of the continental crust. According to our results, in the middle and lower crust, the seismic anomalies beneath the Gulf of Aqaba seem to delineate a sinistral shift $(\sim 100 \mathrm{~km})$ in the opposite flanks of the fault zone, which is consistent with other estimates of the left-lateral displacement in the southern part of the Dead Sea Transform fault. However, no displacement structures were visible in the uppermost lithospheric mantle.
\end{abstract}

\section{Introduction}

Tectonic activity in the Gulf of Aqaba region is responsible for high levels of seismicity, which represent a significant hazard for the local population. For example, in 1993 and 1995, two strong earthquake sequences with magnitudes reaching $\mathrm{Mb}=5.8$ and $\mathrm{Mb}=6.7$ (main shocks), respectively, occurred beneath the Aqaba basin (Abdel Fattah et al., 1997; Hofstetter, 2003). Understanding deep tectonic mechanisms is important for better assessment of the seismic hazard in this region. However, there are still several important questions regarding the geodynamics of the Gulf Aqaba region and surrounding areas that have not been resolved, and these are the active focus of several debates among specialists in different domains of the geosciences. One of the issues relates to the nature of the opening of the Red Sea northern segment. Specifically, it is still unclear whether this feature results from stretching of the continental crust or from spreading and formation of the ocean-type crust. Several other unanswered questions relate to the mechanisms of origin and evolution of the Dead Sea Transform (DST) fault. In particular, it is still debated which portion of the lithosphere (only the crust or the entire lithosphere) is involved in the strikeslip displacement along this fault zone. In addition, there are several alternative hypotheses related to the opening of the deep basins of Aqaba and the Dead Sea along the fault zone. 
Solving these and other geological problems requires robust information on the deep crustal and mantle structures.

Several regional studies were performed for large areas of Asia and Africa that included the region investigated here. Large-scale surface-wave tomography studies by Park et al. (2008) and Chang and van der Lee (2011) did not reveal any particular features related to the Aqaba basin. According to the models of the crustal structure and Moho depth for the entire eastern Mediterranean region by Koulakov and Sobolev (2006) and Mechie et al. (2013), the crust to the north of the Gulf of Aqaba is locally thicker than the crust of other areas. A recently derived seismic model for the upper mantle beneath the Arabian region (Koulakov et al., 2016) gives fair resolution for the Sinai, Aqaba and Dead Sea regions; however, it does not provide any information for structures above a $100 \mathrm{~km}$ depth.

On a crustal scale, there are distinct differences in the number of studies that have previously examined different segments of the DST. The most comprehensive studies have been performed in the area of the Dead Sea (DESERT Group, 2004; Weber et al., 2009). Notably, several passive and active seismic experiments at different scales, receiver function investigations and magneto-telluric studies have provided information on the crustal and upper mantle structures (Ritter et al., 2003; Mechie et al., 2005; Mohsen et al., 2006).

Between the 1960s and 1980s, some reflection and refraction seismic studies used active sources to explore the detailed upper crustal structure beneath the Gulf of Aqaba (Ben-Avraham et al., 1979; Ginzburg et al., 1981; BenAvraham, 1985; Makovsky et al., 2008; Hartman et al., 2014). Seismic refraction data revealed a gradual southward decrease of the Moho depth from $\sim 35 \mathrm{~km}$ at the northern edge of the Gulf of Aqaba to $\sim 27 \mathrm{~km}$ in the southern part. These results helped identify some of the fault structures that can be used to explain the mechanisms of the opening of the Aqaba basin (Fig. 1b).

This overview shows that between detailed seismic surveys of shallow structures in the Aqaba region and largescale regional tomographic models, there is a gap related to studies of the crust and uppermost mantle beneath the Gulf of Aqaba and surrounding areas. Although there is active seismicity in this region and a fair number of seismic stations on both sides of the Gulf of Aqaba, to date, no detailed earthquake tomography work has been performed here. The purpose of this study is to close this gap and to present a new tomographic model based on a large dataset, which was provided by the Egyptian National Seismological Network (ENSN) and complemented with data from the International Seismological Centre (ISC). The 3-D models of $P$ and $S$ velocities allow another look at the structures beneath the Gulf of Aqaba and surrounding regions and enhance our knowledge of the deep mechanisms driving the geodynamic processes in this region.
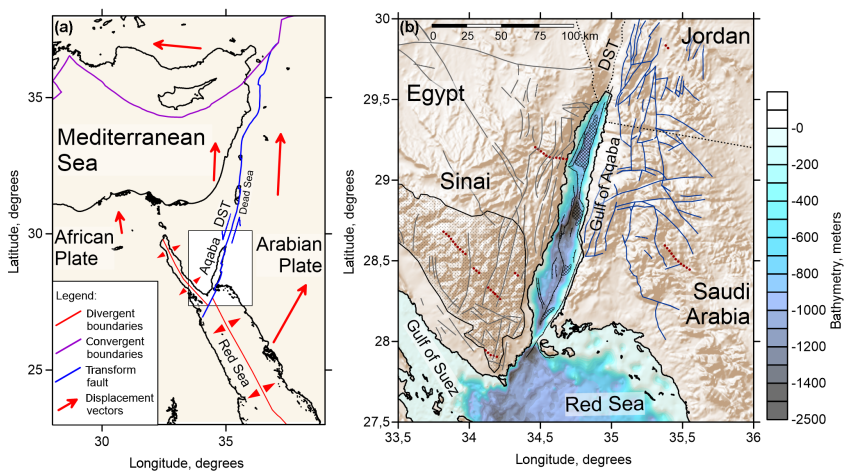

Figure 1. (a) Major tectonic framework of the study area schematically representing the main displacements of the major plates. DST is the Dead Sea Transform fault. (b) Tectonic units in the area of the Gulf of Aqaba. Gray lines are faults in Egypt (Darwish and El Ababy, 1993; Bosworth and McClay, 2001), blue lines are faults in Saudi Arabia and red dotted lines are dykes according to Eyal et al. (1981).

\section{Geological setting}

The Gulf of Aqaba is a basin located at the northern tip of the Red Sea, east of the Sinai Peninsula and west of the Arabian Plate (Fig. 1). With the Gulf of Suez to the west, it extends from the northern portion of the Red Sea. The length of the Gulf of Aqaba is $160 \mathrm{~km}$, and its largest width is $24 \mathrm{~km}$. The maximum floor depth in the gulf reaches $1850 \mathrm{~m}$ (Fig. 1b).

The Gulf of Aqaba represents a transition zone from the spreading zone in the Red Sea to the DST characterized by strike-slip displacement (Ben-Avraham et al., 1979). A very similar transition occurs in the Gulf of California at the southern edge of the San Andreas Fault. Many researchers (Joffe and Garfunkel, 1987; Ehrhardt et al., 2005) accept that the opening of the Gulf of Aqaba occurred simultaneously with the initiation of the DST 20-15 Ma ago. The DST can be traced for more than $1000 \mathrm{~km}$ from the Red Sea to the westernmost end of the Zagros collision zone in eastern Turkey; it cuts the continental crust along the eastern margin of the Mediterranean Sea. Global positioning system (GPS) observations provide rates of the present left-lateral displacement along the DST fault in the range of $3.5-4.0 \mathrm{~mm}$ per year (Wdowinski et al., 2004; Gomez et al., 2007), but geological data provide evidence for faster rates ranging from 5 to $10 \mathrm{~mm}$ per year of long-term displacements in the past starting from the initiation of the DST 20-15 Ma ago (Garfunkel, 1981; Chu and Gordon, 1998). On the basis of geological information, the total displacement in a segment of the DST between the Gulf of Aqaba and the Dead Sea has been estimated to be $105 \mathrm{~km}$ (Freund et al., 1968; Bartov et al., 1980; Garfunkel et al., 1981). To the north of the Dead Sea, the displacement is considerably less (Garfunkel, 1981). 
The initiation of the DST was due to the relative displacements of the African and Arabian plates (Fig. 1a). In the nonet-rotation reference frame, the African and Arabian plates both move northward, but their displacement vectors differ slightly in terms of their magnitudes and orientations (Smith et al., 1994; McClusky et al., 2003). This leads to the divergence of the African and Arabian plates in the area of the Red Sea and results in spreading of this ocean-type basin. In the area of the Dead Sea and to the north, the displacement vectors of these plates are nearly parallel; however, the Arabian Plate moves faster, thus resulting in conditions for transform faulting.

Sharp bathymetry features of the Gulf Aqaba floor and the presence of deep-sea segments reaching depths of $1850 \mathrm{~m}$ (Fig. 1b) provide evidence for ongoing active tectonic processes (Ben-Avraham et al., 1979; Ehrhardt et al., 2005; Makovsky et al., 2008). It appears that in some parts of the Gulf of Aqaba, the sedimentation rate cannot compensate for the rapid subsidence of the sea floor (Ten Brink et al., 1993). This sedimentation regime differs from the Gulf of Suez, which is located on the other side of the Sinai Peninsula. Many consider the Gulf of Suez to be a zone of ongoing crustal extension (McClusky et al., 2003; Mahmoud et al., 2005), and it is nearly fully covered by young sediments (Cochran and Martinez, 1988; Gaulier et al., 1988).

Although the link between the opening of the Aqaba basin and the initiation of the DST displacement is generally accepted, details of this process are still debated. Most scholars associate the origin of deep linear depressions along the DST, such as the Gulf of Aqaba and the Dead Sea, with the pullapart mechanism (Mann et al., 1983; Makovsky et al., 2008; Petrunin and Sobolev, 2008; Hartman et al., 2014). In this context, lateral displacements along a non-straight fault line should lead to the origin of compression and extension zones at the vicinity of the fault, and many studies have used both numerical modeling (Petrunin and Sobolev, 2008; Petrunin et al., 2012) and geological evidence (Ehrhardt et al., 2005) to demonstrate the possibility of such a scenario. Alternatively, the origin of the present depressions along the DST can be explained by the relative transform-normal extension (Ben-Avraham and Zoback, 1992; Smit et al., 2010) due to relocation of the pole of rotation for the DST at about $5 \mathrm{Ma}$ (Garfunkel, 1981). Geophysical investigations of the crustal and mantle structures are one of the key elements required for deciphering the puzzle of the tectonic history of this region.

\section{Seismic data}

In this study, we used the arrival times of $P$ and $S$ seismic waves from earthquakes occurring beneath the Gulf of Aqaba and surrounding regions for the analyses. The dataset was mostly extracted from the catalogs of the ENSN, and it was complemented by data from the ISC catalogs to enlarge the study area and improve the data sampling. The distributions of the stations corresponding to both databases are depicted in Fig. 2 with different colors. We cross-checked the different events recorded in the ENSN network with the ISC catalog. In case of duplicate information on the recorded phases or events, only the ENSN data were taken into consideration. Stations available only in the ISC catalog were also included in the final dataset. The quality control for the combined data was performed at the stage of source location. To remove outliers from the data, we selected the recorded phases with absolute residuals of less than 1.5 and $2 \mathrm{~s}$ for the $P$ and $S$ data, respectively, which corresponded to the stage of source location in the initial 1-D velocity model. These threshold values correspond to the estimated values of residuals along the existing $P$ and $S$ wave data caused by expected heterogeneities in the study area.

The data used in this study are part of a dataset that covers a much larger area than the region presented in the resulting maps (Fig. 2). The same dataset was used in a recent study by El Khrepy et al. (2016), who provided information on the crustal and uppermost seismic structures beneath the Gulf of Suez. The data for this study were recorded by approximately 300 seismic stations in Egypt and surrounding countries; of these stations, only 53 were located in the study region (right panel in Fig. 2). Using the stations and events from a much larger area surrounding the region of interest enabled us to improve the azimuthal coverage and increase the number of recorded phases for some events. The tomographic inversion was performed for the whole area with sufficient ray coverage that was much larger than the area presented in this study. This allowed us to improve locations of events using the ray paths traveling outside our area of interest.

In total, we used more than 9000 events from an area covering all of Egypt (Fig. 2), of which approximately 3000 events corresponded to the Aqaba region and northern Red Sea. To select the data for tomography analyses, we used a criterion of a minimum of six picks for any phase ( $P$ or $S$ ) per event. In total, we selected $\sim 65000 P$ picks and $\sim 17000 S$ picks, with an average of nine picks per event. The relatively small ratio of average number of picks per event was due to the sparse distribution of stations and mostly low magnitudes of events. For most of the ray paths $(85 \%)$, the epicentral distances were less than $300 \mathrm{~km}$; however, data with distances of up to $700 \mathrm{~km}$ did exist, and these data provided us with information about the upper mantle. At the distances of up to $100 \mathrm{~km}$, the distributions of travel times correspond to the crust with apparent velocities of around 6.1 and $3.37 \mathrm{~km} \mathrm{~s}^{-1}$ for the $P$ and $S$ data, respectively. For the larger distances, the travel times correspond to the mantle velocities: 7.9 and $4.57 \mathrm{~km} \mathrm{~s}^{-1}$.

\section{Algorithm for tomographic inversion}

The tomographic inversion was performed by using LOTOS (Local Tomography Software) code (Koulakov, 2009) 

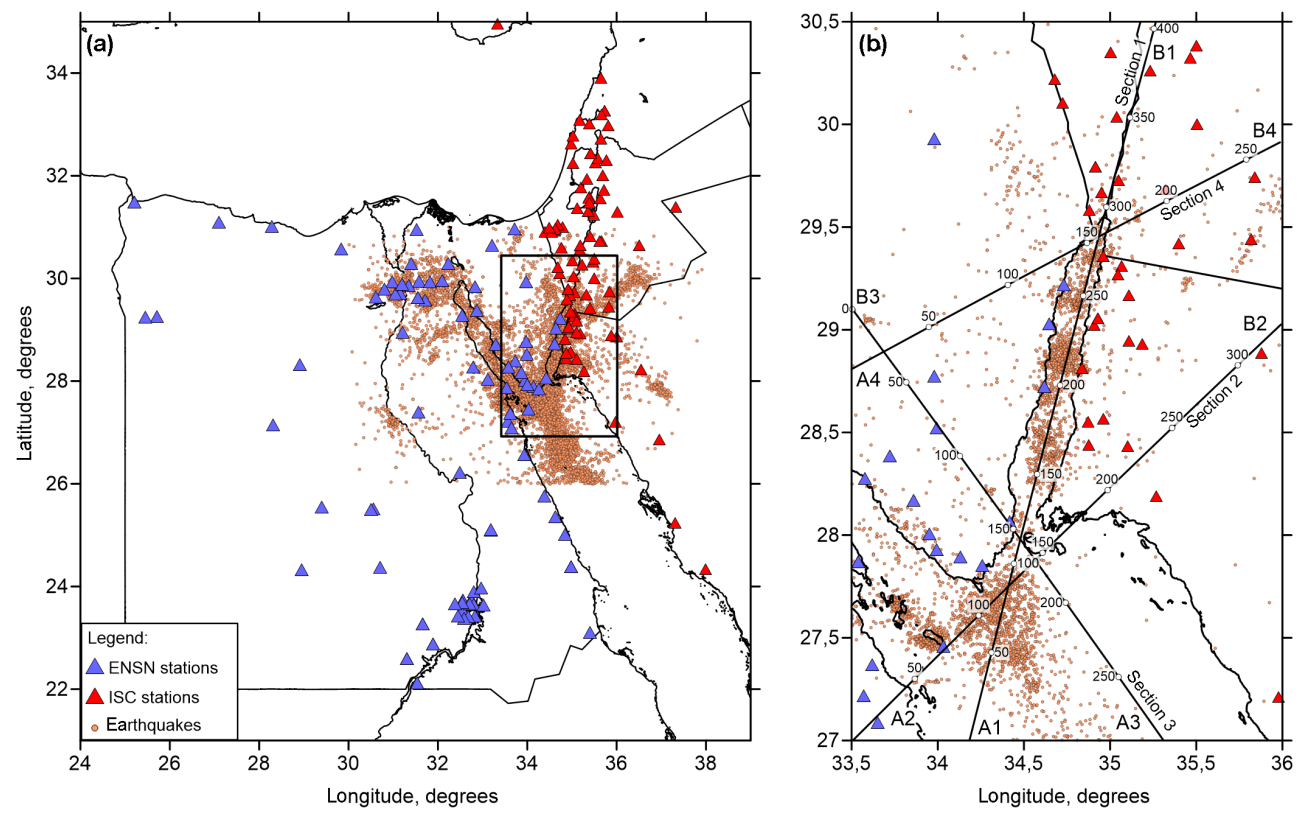

Figure 2. Distributions of seismic stations from the ENSN catalog and ISC catalog. (a) Map of the entire network at the regional scale. (b) Stations and events within the study area. Orange dots represent the following types of seismicity: all events collected from the ENSN catalog (a) and selected relocated events used in this study (b). Locations of the profiles, for which the vertical sections will be presented, are shown in (b).

expanded for the case of large areas. This algorithm accounts for the curvature of the Earth when computing the travel times of seismic rays. This is especially important for rays with long offsets displaying regular bias if sphericity is not taken into account (in a flat model, travel times are always slower). The details of this code have been described in the literature (Koulakov, 2009) and on a website available at http://www.ivan-art.com/science/LOTOS/. Here, we only briefly present the major steps and features. The workflow begins with a preliminary calculation of source locations based on the grid search method. For faster calculations, we approximated the model travel times by using a set of tabulated values derived at a preliminary stage. Then, the locations of sources were recomputed by using the 3-D raytracing algorithm based on the "bending method" (Um and Thurber, 1987). The 3-D velocity distribution was parameterized with nodes that were distributed in the study area according to the density of rays, which is computed as the sum of ray path lengths in a cell of a fixed size $(10 \times 10 \times 3 \mathrm{~km}$ in our case). The nodes were installed only in areas with sufficient data coverage (with ray densities larger than $10 \%$ of the total average value). In the vertical direction, the distance between nodes was inversely dependent on the ray density, but it could not be less than $3 \mathrm{~km}$. In horizontal directions, the grid spacing was defined as $10 \mathrm{~km}$. The numbers of parameters for the $P$ and $S$ models were $\sim 18600$ and $\sim 10600$, respectively. An example of the parameterization node distribution, together with the ray paths, is presented in Fig. 3. To reduce grid dependency, we performed the inversions for four differently oriented grids with basic orientations of $0,22,45$ and $67^{\circ}$ and then averaged the results. The inversion was performed simultaneously for 3-D $P$ and $S$ anomalies, source corrections (four parameters including coordinates and origin time corrections for each source) and station corrections. The velocity solution was damped by a smoothing matrix, which minimized the velocity gradients between all neighboring parameterization nodes. No damping for the $\mathrm{Vp} / \mathrm{Vs}$ ratio was implemented. In this sense, the $P$ and $S$ anomalies were inverted almost independently (they were only slightly linked through the source parameters). The inversion was performed by using the LSQR algorithm (Paige and Saunders, 1982; Nolet, 1987). The steps involving source locations in the derived 3-D models, the calculation of the first derivative matrix and the inversion were iterated five times (a compromise between the computing time and accuracy of the solution). The values of free parameters (e.g., weights for smoothing, station and source corrections given in Table 1) were determined based on the results of synthetic modeling.

The data analysis began with finding an optimal starting velocity model. We used a fairly simple approximation that employed a 1-D distribution of $P$ velocity and a constant value of the $\mathrm{Vp} / \mathrm{Vs}$ ratio. The $P$ velocity was defined in several depth levels; between these depths, the velocity was linearly interpolated. The optimal model was determined by using the trial and error method. The initial location of sources (i.e., grid search with tabulated travel times) was performed in approximately 20 different models by using different $P$ velocities and $\mathrm{Vp} / \mathrm{Vs}$ ratios. In each case, we changed 

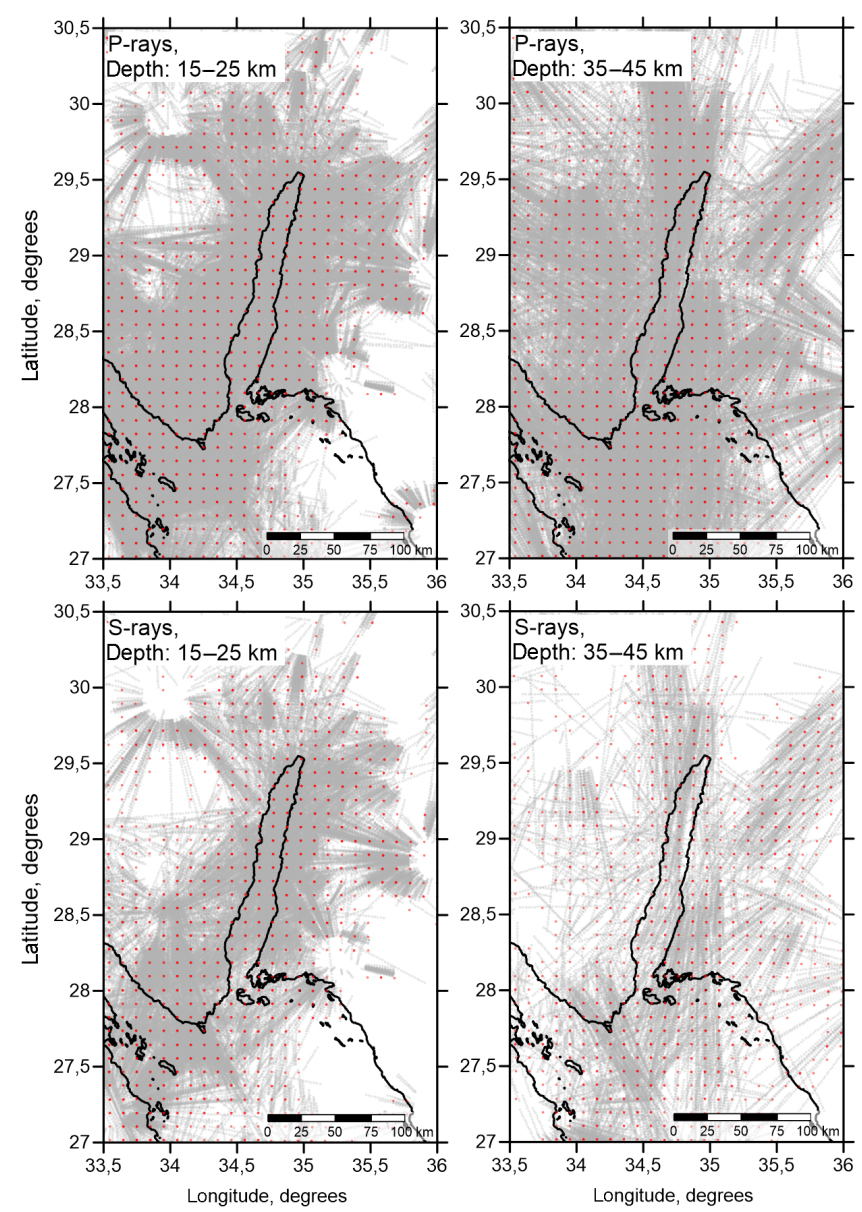

Figure 3. Distributions of the ray paths (gray dots) and nodes of the parameterization grid (red dots). Depth intervals and types of data are indicated on the top left of the maps.

Table 1. Values of some parameters used to calculate the main tomographic model.

\begin{tabular}{ll}
\hline Parameter description & Value \\
\hline Grid spacing, horizontal & $10 \mathrm{~km}$ \\
Minimum grid spacing, vertical & $3 \mathrm{~km}$ \\
Minimum number of picks per event & 6 \\
Maximum residual deviation, $P$ and $S$ & 1.5 and $2 \mathrm{~s}$ \\
Smoothing for the $P$ velocity & 1.5 \\
Smoothing for the $S$ velocity & 3 \\
Station corrections, $P$ and $S$ & 0.1 and 0.3 \\
Weight for the source coordinate correction & 5 \\
Weight for the source origin time correction & 5 \\
\hline
\end{tabular}

the values of the $\mathrm{Vp} / \mathrm{Vs}$ ratio and $P$ velocity at one or several depths and then performed the location of events in the model. The best model was the one that provided the minimum number of rejected outliers and minimum values of average residual deviations. Furthermore, we made several trials of full iterative tomographic inversion to be sure that the
Table 2. The optimal 1-D $P$ velocity distribution used as a reference model for the tomographic inversion.

\begin{tabular}{rc}
$\begin{array}{r}\text { Depth, } \\
\mathrm{km}\end{array}$ & $\begin{array}{c}P \text { velocity, } \\
\mathrm{km} \mathrm{s}^{-1}\end{array}$ \\
\hline-3 & 4.9 \\
10 & 6.0 \\
20 & 6.7 \\
30 & 7.5 \\
50 & 8.0 \\
100 & 8.2 \\
\hline
\end{tabular}

best model provided a similar number of positive and negative anomalies at all depths. Note that we performed the optimization for the entire dataset of the Egyptian networks; so, the resulting heterogeneities within the selected area of interest may appear not perfectly balanced. As a result of these procedures, we obtained an optimal $\mathrm{Vp} / \mathrm{Vs}$ value of 1.74 and the $P$ velocity distribution presented in Table 2 .

\section{Results}

\subsection{Resolution tests}

Before discussing the main velocity models, we present the results of synthetic tests used to assess the horizontal and vertical resolution. Synthetic data were computed by using the same ray configuration as that in the observed data catalog used to calculate the main tomography model. The synthetic travel times were calculated by using the algorithm for 3$\mathrm{D}$ ray-tracing based on the bending method. Random noise with a magnitude of $0.15 \mathrm{~s}$ was added to the synthetic travel times. Before starting the reconstruction, we perturbed the locations of events and origin times so their true values remained unknown. The reconstruction procedure included all of the steps performed during the LOTOS code procedure described in Sect. 4, including the preliminary location identification of sources in the starting 1-D model. This step strongly biases the synthetic residuals and leads to a trade-off between the source and velocity parameters, similar to the processing of observed data. These synthetic tests helped us to derive the most optimal values for the inversion parameters, thus enabling the highest quality of reconstruction. The parameters were then used to perform the inversion of the observed data.

Here, we present results for three synthetic models. The first model (Fig. 4) was used to assess the horizontal resolution. In this case, cells with positive and negative anomalies with an amplitude of $\pm 5 \%$ and a size of $50 \mathrm{~km} \times 50 \mathrm{~km}$ were defined without depth changes. The synthetic anomalies were added to the reference 1-D velocity model with the constant $\mathrm{Vp} / \mathrm{Vs}$ ratio. In this specific case, the reference model is presumed to be known. The results in Fig. 4 show 

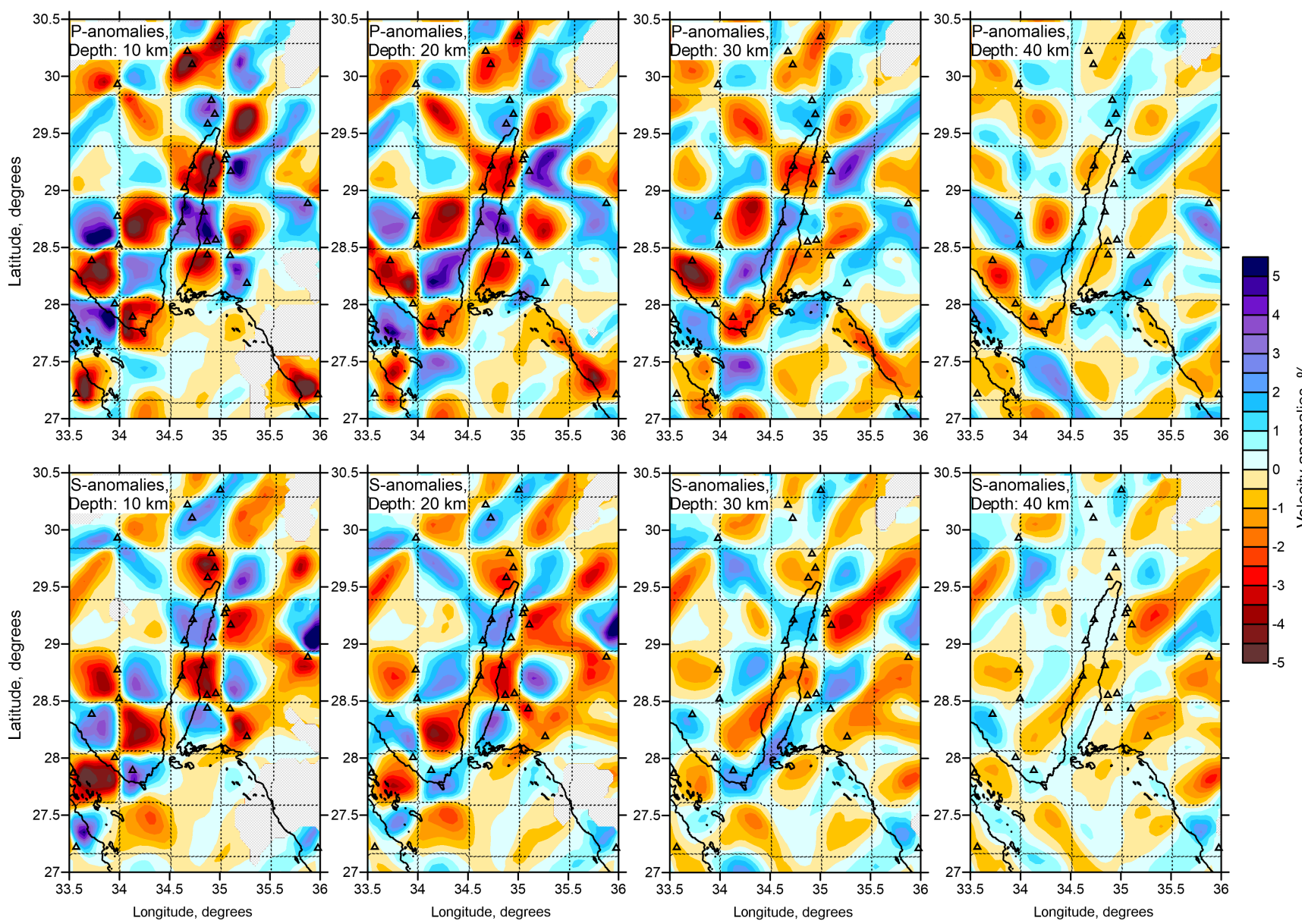

Figure 4. Results of the checkerboard test with the model unchanged with depth for $P$ and $S$ velocity anomalies. The recovered velocity anomalies are presented in four depth sections. Dotted lines indicate the configurations of the "true" synthetic patterns. Triangles depict seismic stations.

that this model generally recovered the anomalies well in most parts of the study area. The best resolution was achieved beneath Sinai and the Gulf of Aqaba, where we were able to restore both the shape and amplitudes of the anomalies. We also tried other checkerboard anomalies and found that patterns with smaller sizes of $25-30 \mathrm{~km}$ were still detectable in these areas. It is interesting that beneath the northern margin of the Red Sea, where we do not have stations, the synthetic structures can still be resolved correctly. At deeper sections $(40 \mathrm{~km})$, we observed some loss of resolution throughout the study area. However, while performing other tests with larger anomalies, we found that a fair resolution at 40 and $50 \mathrm{~km}$ depth could be achieved for pattern sizes starting from 80 to $90 \mathrm{~km}$.

The second model (Fig. 5) aimed to estimate the vertical resolution. Because of the trade-off between the source and velocity parameters, in most cases of earthquake tomography analysis, the vertical resolution is much poorer than the horizontal resolution. In this test, we defined checkerboard anomalies along the same vertical sections that were used for presenting the main results. Across the section, the thickness of anomalies was $40 \mathrm{~km}$. To avoid overlapping synthetic anomalies in the case of intersections of different sections, we performed separate calculations for four models in which the synthetic anomalies were defined along a single profile. Here, we show the results for the $P$ model. We see that in most sections, the change in the anomaly sign at $15 \mathrm{~km}$ depth was correctly recovered. The anomalies between 15 and $45 \mathrm{~km}$ were only recovered in the presence of deep earthquakes, and in many cases, they were strongly smeared. Fair recovery of anomalies in this layer was achieved beneath Sinai (left parts of Sects. 3 and 4), where the anomalies appeared to be even clearer than the shallow anomalies above $15 \mathrm{~km}$ depth. The best resolution was achieved beneath the northernmost margin of the Red Sea and southern part of the Gulf of Aqaba, where we were able to resolve the second boundary of change in the anomaly sign at $45 \mathrm{~km}$. This test shows that the vertical resolution is strongly variable; this should be considered when interpreting the results. 

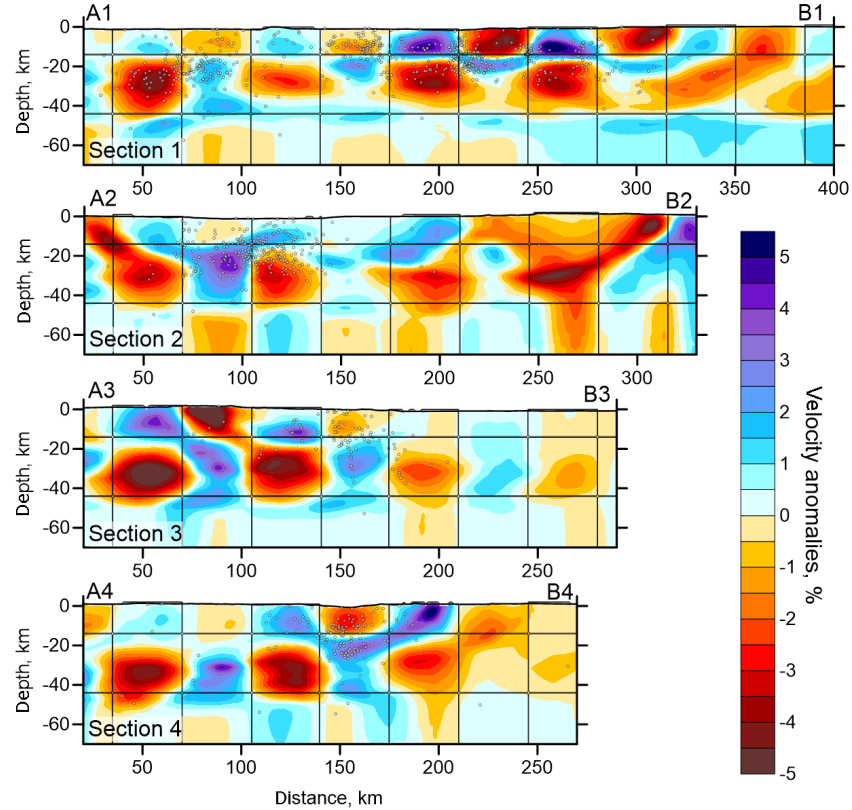

Figure 5. Checkerboard tests with the model changing the sign of anomalies at $20 \mathrm{~km}$ depth. Here, only $P$ velocity anomalies are shown. Locations of the sections are shown in Fig. 2. Thin black lines indicate the configurations of the "true" synthetic patterns. Dots depict projections of seismic events located at the vicinity of the profile.

The last test aimed to check the possibility of restoring the variations of first-order interfaces such as the Moho boundary. Normally, seismic tomography provides continuous velocity distributions, and it cannot be directly used for studying the geometry of interfaces with sharp velocity contrasts. At the same time, velocity variations in the corresponding depth interval may give information about the relative deviations of the interface depth. In the upper plot of Fig. 6, we present a synthetic model representing the crust with variable thickness. In this model, an anomaly of $-20 \%$ defined within a 3-D polygonal prism representing the crust is superimposed with the reference 1-D velocity distribution. After computing the synthetic travel times, we performed the reconstruction procedure with another 1-D model. The recovered $P$ and $S$ velocity models are shown in the middle and lower plots of Fig. 6. Here, it can be seen that for the $P$ velocity model, the Moho interface can be associated with the isovelocity line at $6.6 \mathrm{~km} \mathrm{~s}^{-1}$ (blue layer). The total variation of the Moho depth of $\sim 20 \mathrm{~km}$ was reconstructed correctly, although the transition zone between "thin" and "thick" crust appeared smoother than that in the synthetic model. For the $S$ model, we detected a general trend of thickening and thinning of the crust, though the absolute variations of the velocity contour lines appeared smaller than the deviations of the Moho in the synthetic model. This test shows that the relative deviations of the main first-order interfaces can be
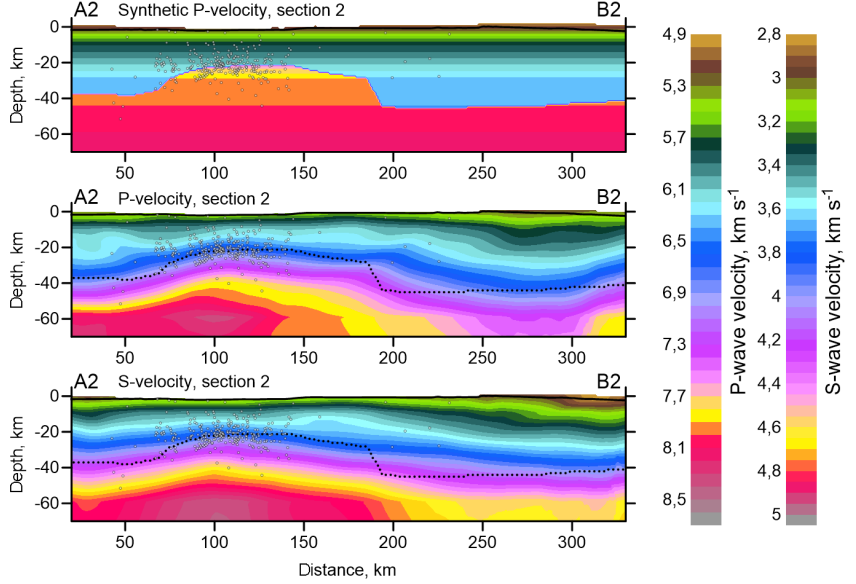

Figure 6. Synthetic test on recovering the Moho depth variations in Sect. 2 (see Fig. 2 for the location of the profile). The upper plot shows the synthetic model; the middle and lower plots show the reconstruction results for the $P$ and $S$ velocities, respectively. The dotted line depicts the synthetic Moho interface, and dots depict the earthquakes used for inversion.

investigated based on the consideration of absolute velocities in vertical sections.

\subsection{Inversion results}

For the inversion of observed data, five iterations were performed. During the inversions, the average absolute residuals were reduced from 0.232 to $0.173 \mathrm{~s}(25.5 \%)$ for the $P$ data and from 0.348 to 0.208 s $(40.2 \%)$ for the $S$ data. The values of the final residuals were generally compatible with the picking accuracy estimates reported by the ENSN (0.1-0.15 s for the $P$ phases and $0.15-0.2$ for the $S$ phases). The larger reduction for the $S$ data seems to be paradoxical considering the lower quality of the $S$ picks. However, the $S$ data were more sensitive to velocity anomalies because the same percent value of an anomaly yielded a larger $S$ residual compared with the $P$ residual. In addition, the amplitudes of the $S$ anomalies were usually stronger than those of the $P$ anomalies.

The inversion results for the $P$ and $S$ anomalies are presented in horizontal sections (Fig. 7). For reference, in the section at the $10 \mathrm{~km}$ depth, we show the locations of the main faults. At the 20 and $30 \mathrm{~km}$ depths, we provide reconstruction markers for the left-lateral displacement of the DST, which will be considered in the Discussion (Sect. 6). Velocity anomalies are shown only in areas with a sufficient amount of data. Outside the resolved areas, the anomalies are shaded.

An informal argument for the robustness of the computed tomography models is the clear correlation of the main $P$ and $S$ velocity anomalies that were independent in inversion. Although $P$ and $S$ velocities should not necessarily fit each other, in practice, the main geological structures behave similarly in both cases, especially on a large scale. 

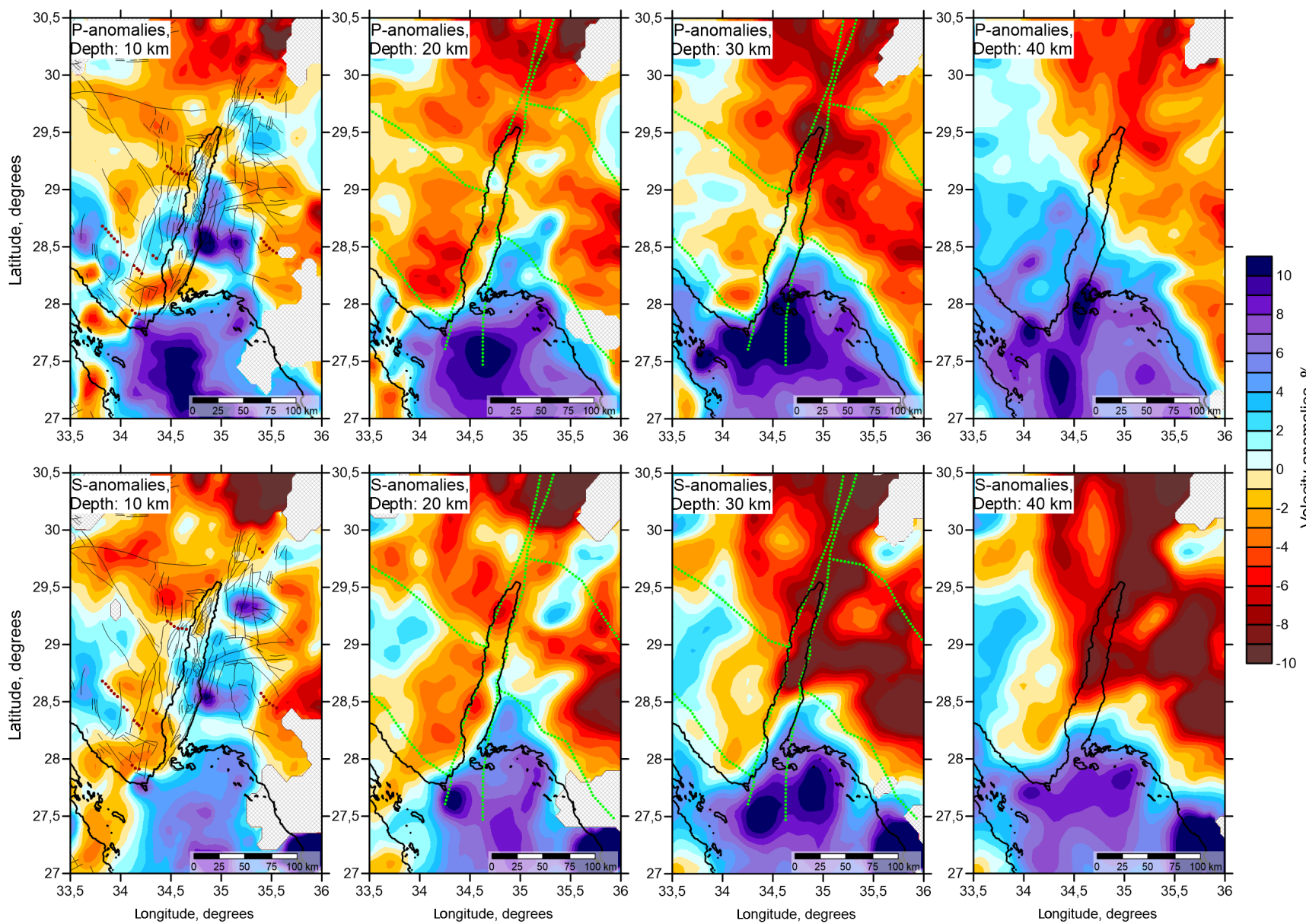

Figure 7. $P$ and $S$ anomalies resulting from the observed data inversion in four horizontal sections. At $10 \mathrm{~km}$ depth, major tectonic units (the same as in Fig. 1b) are shown. In sections at 20 and $30 \mathrm{~km}$ depth, the reference lines marking the displacements along the DST are depicted by green dotted lines.

The most striking feature, which was visible for both $P$ and $S$ anomalies at all depths (Fig. 7), was the prominent high-velocity anomaly beneath the Red Sea. The limits of this anomaly matched with the coastal line (especially at $30 \mathrm{~km}$ depth). The amplitude of this positive anomaly reached $10 \%$. As we can see in the checkerboard tests, the existing data configuration allows for robust recovery of this structure.

At $10 \mathrm{~km}$ depth (left column in Fig. 7), the areas to the north of the Red Sea look patchy, which is possibly indicative of the complex structure of the upper crust in this region. The similarity of the $P$ and $S$ anomalies and best resolution achieved at this depth in the checkerboard tests indicate the robustness of these structures. At $10 \mathrm{~km}$ depth, we did not observe any clear structures associated with the Gulf of Aqaba. The Gulf of Suez at this depth is associated with a low-velocity anomaly.

At $20 \mathrm{~km}$ and deeper, the structures become more regular and less patchy. The Sinai Peninsula at 20 and $30 \mathrm{~km}$ depth (second and third columns in Fig. 7) is mostly asso- ciated with a prominent low-velocity anomaly, whereas at $10 \mathrm{~km}$ depth, we observed complex alternations of positive and negative anomalies. Beneath the onshore areas of Saudi Arabia and along the DST, we observed a large low-velocity anomaly. Together with the Sinai's anomaly, it forms a zigzag (or Z-shaped) structure at 20 and $30 \mathrm{~km}$ depth following the coastal line of Sinai and Arabia.

At $40 \mathrm{~km}$ depth (right column in Fig. 7), the structure becomes rather simple. In the $P$ velocity model, we observed a straight diagonally oriented transition dividing the whole area into two parts, namely, a positive anomaly to the southwest and a negative anomaly to the northeast. In the $S$ velocity model, we still observed a remnant of the Sinai-related negative anomaly, which can be explained by the relatively poor vertical resolution of the $S$ model and downward smearing of crustal anomalies.

Absolute $P$ and $S$ velocities are shown at a $30 \mathrm{~km}$ depth with four vertical sections (Figs. 8 and 9). We have applied a special color scale to help highlight the main geological layers. We assume that the brown color represents sediments, 

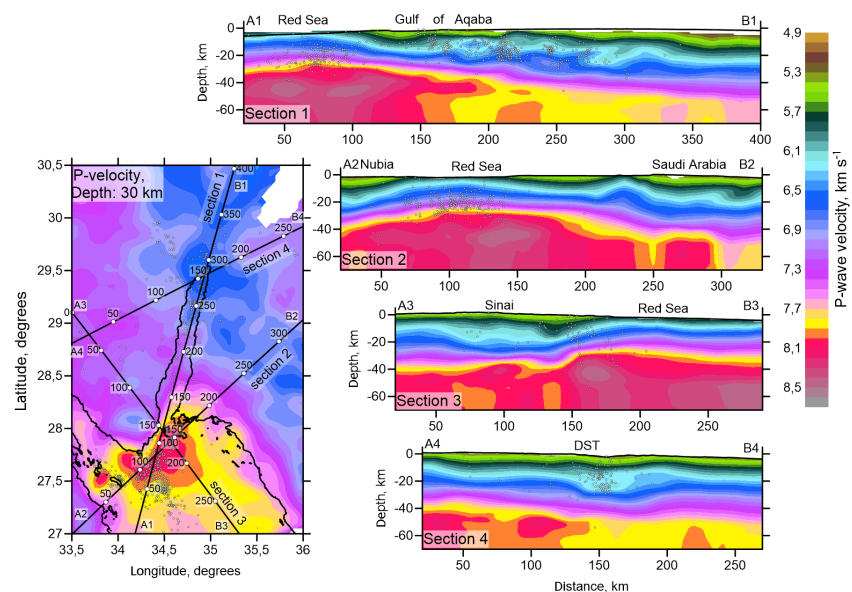

Figure 8. Absolute $P$ velocity at $30 \mathrm{~km}$ depth and in four vertical sections. Locations of the sections are shown in the map. White dots are the projections of earthquakes onto the profiles.

green and light blue are associated with the upper crust, dark blue is the lower crust and red and yellow depict the uppermost mantle. Thus, the contour lines in the vertical sections may roughly represent deviations in the main interfaces.

\section{Discussion}

\subsection{Comparison with previous studies}

Previously, tomography results at the crustal and uppermost mantle scales for this region were lacking. While there have been several local-scale offshore experiments in the northern Red Sea and in the Gulf of Aqaba (Ben-Avraham et al., 1979; Ginzburg et al., 1981; Ben-Avraham, 1985; Makovsky et al., 2008; Hartman et al., 2014), these studies mostly investigated the shallow structures beneath the sea floor that do not intersect with the resolved area of our study. The distributions of velocity anomalies shown in Fig. 7 can be compared with previous results on larger scales based on different methods. For example, in the regional tomography model by Chang and van der Lee (2011), the study area is entirely located within one large low-velocity pattern. Some similarities can be observed with the seismic velocity anomalies for the Aqaba region in the model by Koulakov and Sobolev (2006), which was based on data from the ISC catalogs, especially for the distributions of the $S$ anomalies. However, that area was on the margin of the model and thus had lower data density and poorer resolution. For the upper mantle, the $P$ velocity model is similar to a recent tomography model of the entire Arabian region by Koulakov et al. (2016), in which the southern part of the Gulf of Aqaba corresponds to the higher velocity anomaly at 100 and $200 \mathrm{~km}$ depths. Meanwhile, the large area corresponding to the Dead Sea and surrounding region coincides with the lower velocity anomaly.

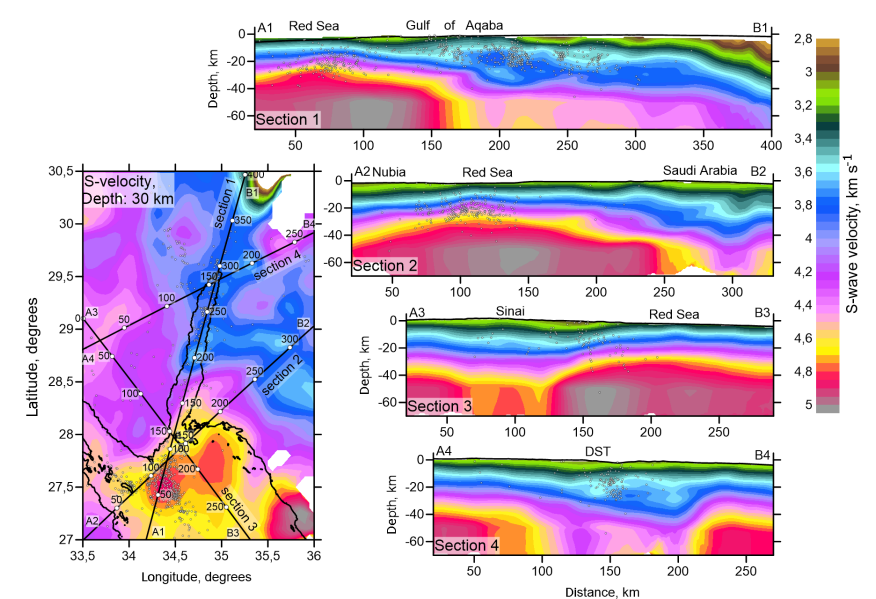

Figure 9. Same as Fig. 8, but for the $S$ absolute velocities.

\subsection{Moho depth variations from tomography}

Normally, seismic tomography cannot be used for determining the depth of the first-order interfaces such as Moho. Specifically, tomography inversion provides the continuous distributions of anomalies for $P$ and $S$ wave velocities and it cannot restore sharp velocity changes. At the same time, some authors claim that in cases of varied interfaces with sufficiently strong velocity contrasts, velocity heterogeneities at corresponding depths may give information about the relative depth variations of the interface. For example, Koulakov et al. (2015), based on tomography work, have produced a map of the Moho depth variations beneath the central Himalayas. In that study, they used synthetic tests to show the resolving capacity and limitations of such an approach. Here we use an approach similar to the one presented in Koulakov et al. (2015) and show that recovery of the Moho depth variations is also possible in our case (Fig. 6).

We propose that the absolute velocities can be used for estimating the Moho depth in the Aqaba region and surrounding areas. In Figs. 8 and 9 with the absolute velocities in vertical sections, we developed a special color scale that facilitates the tracing of certain velocity values possibly representing geological strata. The contour lines of $\mathrm{Vp}=7.3 \mathrm{~km} \mathrm{~s}^{-1}$ and $\mathrm{Vs}=4.3 \mathrm{~km} \mathrm{~s}^{-1}$ (violet layer) are the average values between the lower crust and uppermost mantle and may indicate the deviation of the Moho interface. On the basis of this assumption, we can estimate that beneath the Red Sea, the crustal thickness is approximately $20 \mathrm{~km}$. The largest thickness observed was in the area of the DST (northern part of Sect. 1) and beneath Saudi Arabia (northeastern part of Sect. 2), where the Moho depth reaches $\sim 40 \mathrm{~km}$. A relatively thin crust $(25-30 \mathrm{~km})$ was observed beneath the middle part of Sinai (northwestern part of Sect. 3 and southwestern part of Sect. 4). The maps of absolute velocities at $30 \mathrm{~km}$ may indicate mantle velocities beneath the Red Sea (yellow and 

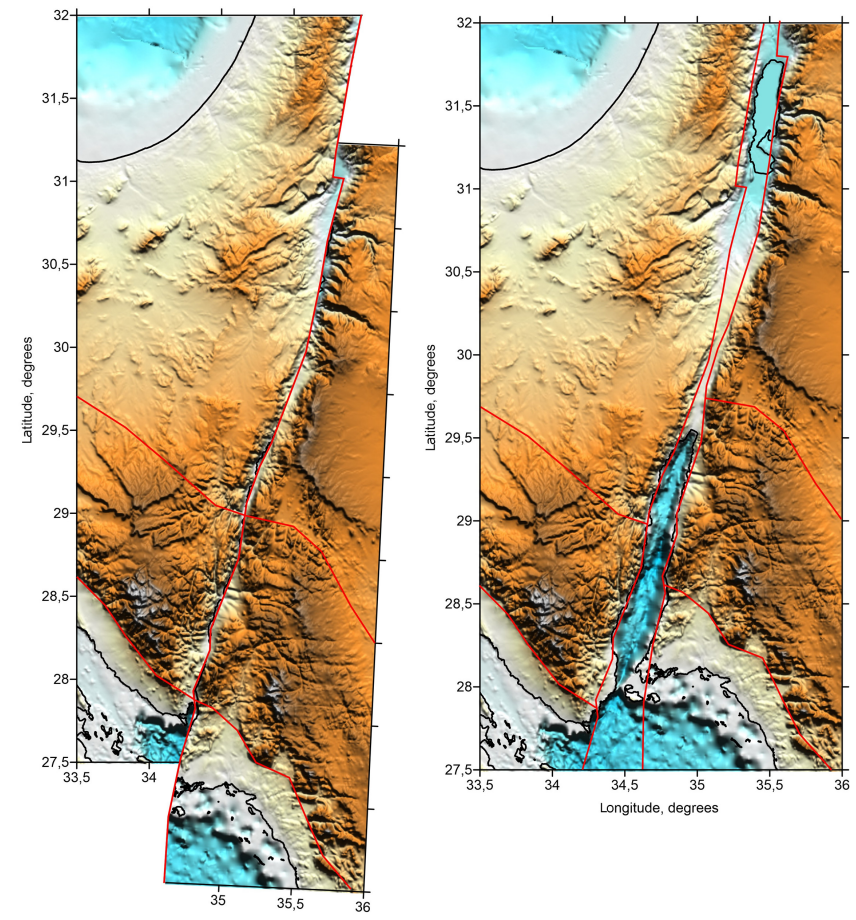

Figure 10. Back-reconstruction of the displacements along the DST since the initiation in the early Miocene (left) (Eyal et al., 1981) and present topography along the DST. Red lines mark the main structures at the initial stage for reference.

red) and crustal velocities in most of the surrounding areas (violet and blue).

Note, however, that these values should be considered as qualitative estimates of the Moho depth variations because of many additional factors that might also affect seismic velocities (such as velocity variations in the crust and mantle).

\subsection{Oceanic crust in the Red Sea}

The main feature, which is clearly observable in both $P$ and $S$ velocity models at all depths, is the strong high-velocity anomaly that corresponds to the Red Sea. At the $30 \mathrm{~km}$ depth, the high velocity in the Red Sea may be related to a significantly thinner crust. In offshore areas, this depth corresponds to the mantle, whereas in continental areas, this is still the lower crust. The same conclusion follows from consideration of the absolute velocities along Sects. 1, 2 and 3 in Figs. 8 and 9. The high-velocity anomalies in the upper sections may support the notion that there is a prevalence of mafic rocks with higher velocities compared with felsic rocks, which is typical for the upper continental crust in surrounding areas (e.g., Rudnick and Fountain, 1995). This fact may renew debates regarding the nature of the crust in the northern Red Sea. According to a concept proposed by some authors (e.g., Cochran and Martinez, 1988) that is based on the absence of clear signatures of spreading ridges and linear
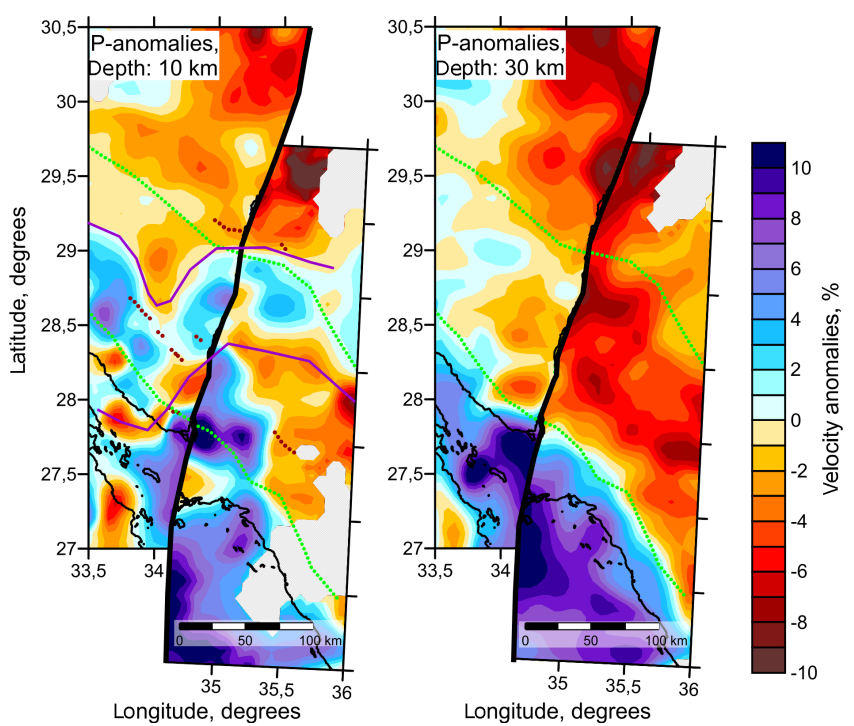

Figure 11. Back-reconstruction of the $P$ velocity model at 10 and $30 \mathrm{~km}$ depth according to the DST displacements presented in Fig. 10. Green dotted lines depict the reference markers for the displacement. Violet lines are the structures discussed in the text. The red dotted lines are dykes according to Eyal et al. (1981).

magnetic anomalies (e.g., McKenzie et al., 1970), the crust in the northern part of the Red Sea was formed as a result of gradual stretching, and thus, it has both felsic and mafic components. However, more recent studies (Cochran, 2005; Cochran and Karner, 2007) report clear axial depression of the bathymetry and aligned magnetic anomalies as well as a chain of dykes that are more typical for rifting processes. In our study, we can see that the high-velocity anomaly in the Red Sea has very sharp bounds coinciding with the coastline; this presumes an abrupt difference in crustal properties between the onshore and offshore areas at all depth intervals. This would mean that the upper felsic crust is almost absent at this area, and this would not be possible in the case of gradual stretching of the continental crust. We propose that such slow spreading might originate from a dispersed system of dykes covering large areas of the sea bottom. However, to prove this hypothesis, additional studies in other disciplines are needed.

At $40 \mathrm{~km}$ depth, the structure corresponds with the uppermost mantle. As observed in synthetic tests, the vertical resolution of the $S$ model at this depth is poor. Therefore, it might be affected by the vertical smearing of crustal structures and the corresponding results do not accurately represent the distribution in the mantle. At the same time, the mantle structure for the $P$ velocity appears to be robust. The presence of high velocities in the uppermost mantle beneath the northern Red Sea at this depth does not confirm the hypothesis of significant hot asthenosphere upwelling, which would exist in the case of active rifting. This result supports the passive nature of the extension, which is likely due to relative displacements 
of large lithospheric plates, namely, the African and Arabian plates. This looks consistent with the results of regional tomography work by Koulakov et al. (2016) in which the Red Sea is associated with high-velocity anomalies in the upper mantle.

\subsection{Initiation and development of the DST}

Our seismic tomography model provides new information on the crustal and uppermost mantle structures that may help to elucidate the details of the initiation of the DST fault and opening of the Gulf of Aqaba. In Fig. 10, we present the reconstruction of the displacements along the DST merely based on the analysis of the topography features that provide the most consistent fit of the basin limits. In this simple "scissor and paper" model, we do not consider the difference in slip rate along the DST, which seems to be not significant between the Dead Sea and Gulf of Aqaba (Garfunkel, 1981). We can see that the present locations of depressions along the DST can be explained by the relative transformnormal extension (Ben-Avraham and Zoback, 1992; Smit et al., 2010) caused by the relocation of the pole of rotation for the DST at about $5 \mathrm{Ma}$ (Garfunkel, 1981). The left plot in Fig. 10 depicts a possible structure before the initiation of the DST. In this reconstruction, the coastal structures form continuous trends in NW-SE directions, which are indicated with red lines. According to our reconstruction, the present configuration, shown in the right plot in Fig. 10, was obtained by a left-lateral displacement of the Arabian Plate to $\sim 100 \mathrm{~km}$ with a simultaneous counterclockwise rotation to $2.7^{\circ}$. The total displacement is generally consistent with estimates made by other researchers, based on the similarity of geological strata (Freund et al., 1968). In this plot, red lines along the DST mark the location of the initial fault in the opposite flanks. Between these lines, there are extension zones that correspond to the Gulf of Aqaba and the Dead Sea. This reconstruction demonstrates the origin of the Aqaba basin resulting from simultaneous relative rotation of the Arabian Plate and an offset along the DST. For the Dead Sea, we have defined a step-shaped feature on the fault that facilitates the extension due to the pull-apart mechanism (e.g., Petrunin and Sobolev, 2008).

Here, a natural question arises: can we detect the traces of this displacement in the crustal and uppermost mantle structures based on our tomography results? In Fig. 11, we present the back-reconstruction of the $P$ velocity seismic structures in the upper and lower crust corresponding to the lateral displacement modeled in Fig. 10. In the shallow crust (left column in Fig. 7), except for the large high-velocity anomaly beneath the Red Sea, the structures of the $P$ and $S$ anomalies are unexpectedly inconsistent with the distribution of the main geologic units. Neither the location of the Gulf of Aqaba nor the distributions of the main faults indicated on the maps at $10 \mathrm{~km}$ depth can be unambiguously associated with seismic anomalies. The seismic patterns in the Aqaba area look patchy and non-structured. However, as shown in the left panel of Fig. 11, after shifting the eastern flank with respect to the western one according to our backreconstruction model, the structures become more consistent. For example, the negative seismic anomalies at the $10 \mathrm{~km}$ depth seem to form two continuously curved zones, which are highlighted with violet lines that appear to be nearly parallel. We may hypothesize that these anomalies represent hidden geological structures that existed in the crust prior to the initiation of the DST fault. Note also that after backdisplacement along the DST fault, the dykes identified by Eyal et al. (1981) (red dotted lines in the left plot of Fig. 11) seem to form consistent structures aligned parallel to the coast.

In sections at depths of 20 and $30 \mathrm{~km}$ in Fig. 7, we depict the markers of the lateral displacements since the initiation of the Dead Sea Fault with green dotted lines. The line along the coast, which has a step-shaped form after $\sim 100 \mathrm{~km}$ of left-lateral displacement, almost perfectly fits the transition between high- and low-velocity anomalies. In the right panel in Fig. 11, we present the seismic structure corresponding to the stage just before initiation of the DST. Here, it can be seen that the transition between high- and low-velocity patterns looks almost straight. These reconstructions correspond well to the total estimates of the lateral displacements along the DST derived from independent sources.

\subsection{Traces of the Aqaba and DST in the crust and mantle}

The lack of a prominent anomaly beneath Aqaba (left column in Fig. 7), which was expected at shallow depths because of the sediments, may indicate a relatively thin sedimentary cover that does not considerably contribute to the seismic model. The Gulf of Aqaba has generally deep bathymetry, which indicates that the rate of extension here exceeds the sedimentation rate. According to seismic surveys by BenAvraham et al. (1979), the maximum thickness of sediments in the Aqaba basin may reach $2-3 \mathrm{~km}$, but the thickness appears to be strongly variable. The sedimentation in the Aqaba basin appears similar to the average sedimentary cover thickness in the surrounding onshore areas and thus does not produce a prominent relative negative anomaly in the shallow velocities. Furthermore, the ray configuration used in this study does not allow for the recovery of shallow anomalies in the offshore areas. This can be compared with tomography results for the shallow water basin of the Gulf of Suez (left column in Fig. 7), which is completely covered with sediments and is where we observed a shallow low-velocity anomaly both in the $P$ and $S$ velocity models.

At deeper sections (second and third columns in Fig. 7), we observed a negative anomaly along the northern segment of the Gulf of Aqaba and the DST, which is especially clear for the $S$ velocity model at $30 \mathrm{~km}$ depth in Fig. 7. This structure possibly indicates crustal thickening and local heat- 
ing due to the slip-parallel extension of the basin. However, seismic anomalies only indirectly represent crustal thickness variations, and they are sensitive to only large deviations of the Moho depth. Other methods such as seismic reflection surveys or receiver function analysis would be more suitable for this purpose.

We can see that at $40 \mathrm{~km}$ depth (right column in Fig. 7), which corresponds to the uppermost mantle, the structure of $P$ velocity anomalies is different from those in the lower crust and transition zone. This difference is less prominent for the $S$ velocity, probably because of the poorer vertical resolution that smears down the crustal anomalies to the mantle. In the $P$ velocity model, instead of the step-shaped contact zone identified at the $30 \mathrm{~km}$ depth, we observed a nearly linear transition oriented SSE-NNW between high velocities to the southwest and lower anomalies to the northeast. The shape of this boundary looks very similar to that in the lowercrustal model after back-reconstruction as shown in the right panel Fig. 11. Thus, these findings seem to indicate that the uppermost mantle conserves its structure regardless of slip displacements along the DST. Note that the orientation of the transition between high- and low-velocity anomalies appears to be nearly perpendicular to the general direction of horizontal smearing identified in synthetic modeling; thus it cannot be an artifact due to poor horizontal resolution.

There are other lines of evidence that show the DST does not affect the mantle structures significantly. For example, the regional tomography model of the eastern Mediterranean by Koulakov and Sobolev (2006) shows a zone of relatively low $P$ wave velocity to the north of Aqaba continuously crossing the fault. Teleseismic tomography for the Dead Sea area (Koulakov et al., 2006) also did not reveal any faultrelated structures in the upper mantle. It is important that the existing models of the Moho depth in this region (see review in Mechie et al., 2013) do not reveal any clear connection with the displacement along the DST. However, it is not entirely clear how these continuous features in the uppermost mantle could be conserved after more than $100 \mathrm{~km}$ of displacement along the DST fault. All these examples suggest that most of the displacements along the DST occur in the crust, whereas the component of the strike-slip displacement rapidly decays with depth in the mantle lithosphere. Considering the relatively thin lithosphere $(60-70 \mathrm{~km})$, which has a tendency for southward thinning (Mohsen et al., 2006) in this region, one might assume that the anomalies in the mantle are mostly controlled by present-day thermomechanical processes in the lowermost lithospheric mantle and asthenosphere, rather than the displacements along the DST. However, this question still requires further investigations.

It would be interesting to study the relative velocity anomalies beneath Aqaba at depths that fully correspond to the mantle to identify the link between mantle processes and crustal displacements. Unfortunately, the velocity model does not have sufficient resolution for depths greater than $40 \mathrm{~km}$. At our scale and in our area of interest, information on mantle structures can only be derived from the analysis of teleseismic data. Our future work will focus on analyses of the teleseismic records provided by stations distributed over the whole area and on the acquisition of more information on mantle processes beneath the northern part of the Red Sea.

\section{Conclusions}

A large dataset containing the $P$ and $S$ wave arrival times from regional earthquakes provided by the Egyptian National Seismological Network was used for a tomographic investigation of the crustal structure beneath the area of the Gulf of Aqaba and northern Red Sea. The main products of this work included 3-D models of $P$ and $S$ seismic velocities within the crust and uppermost mantle for these regions. The model results have helped us to close the gap between the existing small-scale active source studies of the uppermost crust beneath the offshore areas of the Red Sea and Gulf of Aqaba and large-scale regional mantle models beneath Africa and Arabia derived from the inversion of body and surface wave data.

The new seismic models revealed a strong high-velocity anomaly in the northern Red Sea, with sharp boundaries coinciding with the coastal line. This may be indicative of an oceanic or transitional (mafic-dominated) type of crust and seems to oppose the concept of gradual stretching of the continental crust in the northern Red Sea that has been proposed by some authors. However, the question about the development of the oceanic crust, specifically in regard to the absence of any traces of ridges and spreading centers in the northern Red Sea that would require a rather dispersed extension of oceanic crust as opposed to spreading localized along rifts, still remains unanswered.

As it was demonstrated in synthetic test results shown in Fig. 6, the absolute velocities in vertical sections can be used for estimating the variations of the Moho depth. According to our results, the Moho depth varies from $\sim 20 \mathrm{~km}$ beneath the Red Sea to $\sim 40 \mathrm{~km}$ beneath the Arabian Plate. In this sense, the crust in the Red Sea is not "classically" oceanic, with a typical thickness of $\sim 7 \mathrm{~km}$. At the same time, strong high-velocity anomalies presume that the mafic component prevails here; thus, it cannot be associated with stretching of the continental crust.

In the middle and lower crust, the seismic anomalies seem to delineate a step-shaped pattern, which is indicative of the left-lateral displacement of the crust along the Dead Sea Transform fault. The estimated value of this displacement from the seismic tomography model is approximately $100 \mathrm{~km}$; this is consistent with existing estimates from geological and geomorphology data for the southern part of the DST.

At $40 \mathrm{~km}$ depth, no apparent link between the locations of seismic anomalies and the DST fault zone was observed. Previous studies also did not reveal any fault-related struc- 
tures in the uppermost mantle. This might indicate that the displacement along the DST occurs merely in the crust and decays rapidly with depth. However, this question still requires further investigations.

\section{Data availability}

The data are available at the Egyptian National Seismological Network ENSN, National Research Institute of Astronomy and Geophysics NRIAG, Helwan, Cairo, Egypt, http: //www.nriag.sci.eg/.

Acknowledgements. Earthquake data for this study were obtained from the Egyptian National Seismological Network. Ivan Koulakov was supported by the Russian Science Foundation (grant no. 14-17-00430). The authors extend their appreciation to the Deanship of Scientific Research at King Saud University for funding the work through the research group project RG-1435-027. Alexey G. Petrunin was supported by the German Research Foundation (DFG grant PE 2167/1-1).

Edited by: C. Juhlin

\section{References}

Abdel-Fattah, A. K., Hussein, H. M., Ibrahim, E. M., and El Atta, A. A.: Fault plane solutions of the 1993 and 1995 Gulf of Aqaba earthquakes and their tectonic implications, Ann. Geophys., 40, 1555-1564, doi:10.4401/ag-3831, 1997.

Bartov, Y., Steinitz, G., Eyal, M., and Eyal, Y.: Sinistral movement along the Gulf of Aqaba-Its age and relation to the opening of the Red Sea, Nature, 285, 220-222, 1980.

Ben-Avraham, Z.: Structural framework of the gulf of Elat (Aqaba), northern Red Sea, J. Geophys. Res.-Sol. Ea., 90, 703-726, 1985.

Ben-Avraham, Z. and Zoback, M. D.: Transform-normal extension and asymmetric basins: An alternative to pull-apart models, Geology, 20, 423-426, 1992.

Ben-Avraham, Z., Almagor, G., and Garfunkel, Z.: Sediments and structure of the Gulf of Elat (Aqaba) - northern Red Sea, Sediment. Geol., 23, 239-267, 1979.

Bosworth, W. and McClay, K.: Structural and stratigraphic evolution of the Gulf of Suez rift, Egypt: a synthesis. Mémoires du Muséum national d'histoire naturelle, 186, 567-606, 2001.

Chang, S. J. and van der Lee, S.: Mantle plumes and associated flow beneath Arabia and East Africa, Earth Planet. Sc. Lett., 302, 448454, 2011.

Chu, D. and Gordon, R. G.: Current plate motions across the Red Sea, Geophys. J. Int., 135, 313-328, 1998.

Cochran, J. R.: Northern Red Sea: Nucleation of an oceanic spreading center within a continental rift, Geochem. Geophy. Geosy., 6, Q03006, doi:10.1029/2004GC000826, 2005.

Cochran, J. R. and Karner, G. D.: Constraints on the deformation and rupturing of continental lithosphere of the Red Sea: the transition from rifting to drifting, Geological Society, London, Special Publications, v. 282, 265-289, doi:10.1144/SP282.13, 2007.
Cochran J. R. and Martinez, F.: Evidence from the northern Red Sea on the transition from the continental to oceanic rifting, Tectonophysics, 153, 25-53, 1988.

Darwish, M. and El Araby, A.: Petrography and diagenetic aspects of some siliciclastic hydrocarbon reservoirs in relation to rifting of the Gulf of Suez, Egypt. Geodynamics and sedimentation of the Red Sea-Gulf of Aden Rift System. Geologic Survey Egypt Special Publication, 1, 155-187, 1993.

DESERT Group: The crustal structure of the Dead Sea Transform, Geophys. J. Int., 156, 655-681, doi:10.1111/j.1365246X.2004.02143.x, 2004.

Ehrhardt, A., Hubscher, C., Ben-Avraham, Z., and Gajewski, D.: Seismic study of pull-apart-induced sedimentation and deformation in the Northern Gulf of Aqaba (Elat), Tectonophysics, 396, 59-79, 2005

El Khrepy, S., Koulakov, I., and Al-Arifi, N.: Crustal structure beneath the continental rifting area of Gulf of Suez from earthquakes tomography, Tectonophysics, 668-669, 92-104, doi:10.1016/j.tecto.2015.11.027, 2016.

Eyal, M., Eyal, Y., Bartov, Y., and Steinitz, G.: The tectonic development of the western margin of the Gulf of Elat (Aqaba) rift, Tectonophysics, 80, 39-66, 1981.

Freund, R., Zak, I., and Garfunkel, Z.: Age and rate of the sinistral movement along the Dead Sea rift, Nature, 220, 253-255, 1968.

Garfunkel, Z.: Internal structure of the Dead Sea leaky transform (rift) in relation to plate kinematics, Tectonophysics, 80, 81-108, 1981.

Garfunkel, Z., Zak, I., and Freund, R.: Active faulting in the Dead Sea rift, Tectonophysics, 80, 1-26, 1981.

Gaulier, J. M., Le Pichon, X., Lyberis, N., Avedik, F., Geli, L., Moretti, I., Deschamps, A., and Hafez, S.: Seismic study of the crust of the northern Red Sea and Gulf of Suez, Tectonophysics, $153,55-88,1988$.

Ginzburg, A., Makris, J., Fuchs, K., and Prodehl, C.: The structure of the crust and upper mantle in the Dead Sea rift, Tectonophysics, 80, 109-119, 1981.

Gomez, F., Karam, G., Khawlie, M., McClusky, S., Vernant, P., Reilinger, R., Jaafar, R., Tabet, C., Khair, K., and Barazangi, M.: Global Positioning System measurements of strain accumulation and slip transfer through the restraining bend along the Dead Sea fault system in Lebanon, Geophys. J. Int., 168, 1021-1028, 2007.

Hartman, G., Niemi, T. M., Tibor, G., Ben-Avraham, Z., AlZoubi, A., Makovsky, Y., Akawwi, E., Abueladas, A.-R., and AlRuzouq, R.: Quaternary tectonic evolution of the Northern Gulf of Elat/Aqaba along the Dead Sea Transform, J. Geophys. Res.Sol. Ea., 119, 9183-9205, doi:10.1002/2013JB010879, 2014.

Hofstetter, A.: Seismic observations of the 22/11/1995 Gulf of Aqaba earthquake sequence, Tectonophysics, 369, 21-36, 2003.

Joffe, S. and Garfunkel, Z.:, Plate Kinematics of the circum Red Sea - a re-evaluation, Tectonophysics, 141, 5-22, 1987.

Koulakov, I.: LOTOS code for local earthquake tomographic inversion. Benchmarks for testing tomographic algorithms, B. Seismol. Soc. Am., 99, 194-214, doi:10.1785/0120080013, 2009.

Koulakov, I. and Sobolev, S. V.: Moho depth and three-dimensional $\mathrm{P}$ and $\mathrm{S}$ structure of the crust and uppermost mantle in the Eastern Mediterranean and Middle East derived from tomograpic inversion of local ISC data, Geophys. J. Int., 164, 1, 218-235, 2006.

Koulakov, I., Sobolev, S. V., Weber, M., Oreshin, S., Wylegalla, K., and Hofstetter, R.: Teleseismic tomography reveals no signature 
of the Dead Sea Transform in the upper mantle structure, Earth Planet. Sc. Lett., 252, 189-200, 2006.

Koulakov, I., Maksotova, G., Mukhopadhyay, S., Raoof, J., Kayal, J. R., Jakovlev, A., and Vasilevsky, A.: Variations of the crustal thickness in Nepal Himalayas based on tomographic inversion of regional earthquake data, Solid Earth, 6, 207-216, doi:10.5194/se-6-207-2015, 2015.

Koulakov, I., Burov, E., Cloetingh, S., El Khrepy, S., Al-Arifi, N., and Bushenkova, N.: Evidence for anomalous mantle upwelling beneath the Arabian Platform from travel time tomography inversion, Tectonophysics, 667, 176-188, 2016.

Mahmoud, S., Reilinger, R., McClusky, S., Vernant, P., and Tealeb, A.: GPS evidence for northward motion of the Sinai Block: Implications for E. Mediterranean tectonics, Earth Planet. Sc. Lett., 238, 217-224, 2005.

Makovsky, Y., Wunch, A., Ariely, R., Shaked, Y., Rivlin, A., Shemesh, A., Ben Avraham, Z., and Agnon, A.: Quaternary transform kinematics constrained by sequence stratigraphy and submerged coastline features, The Gulf of Aqaba, Earth Planet. Sc. Lett., 271, 109-122, 2008.

Mann, P., Hempton, M. R., Bradley, D. C., and Burke, K.: Development of pull-apart basins, J. Geol., 91, 529-554, 1983.

McClusky, S., Reilinger, R., Mahmoud, S., Ben Sari, D., and Tealeb, A.: GPS constraints on Africa (Nubia) and Arabia plate motions, Geophys. J. Int., 155, 126-138, 2003.

McKenzie, D. P., Davies, D., and Molnar, P.: Plate tectonics of the Red Sea and East Africa, Nature, 226, 243-248, 1970.

Mechie, J., Abu-Ayyash, K., Ben-Avraham, Z., El-Kelani, R., Mohsen, A., Rumpker, G., Saul, J., and Weber, M.: Crustal shear velocity structure across the Dead Sea Transform from twodimensional modelling of DESERT project explosion seismic data, Geophys. J. Int., 160, 910-924, doi:10.1111/j.1365246X.2005.02526.x, 2005.

Mechie, J., Ben-Avraham, Z., Weber, M., Götze, H.-J., Koulakov, I., Mohsen, A., and Stiller, M.: The distribution of Moho depths beneath the Arabian plate and margins, Tectonophysics, 609, 234249, doi:10.1016/j.tecto.2012.11.015, 2013.

Mohsen, A., Kind, R., Sobolev, S. V., Weber, M., and the DESERT Group: Thickness of the lithosphere east of the Dead Sea Transform, Geophys. J. Int., 167, 845-852, doi:10.1111/j.1365246X.2006.03185.x, 2006.

Nolet, G.: Seismic wave propagation and seismic tomography, in: Seismic tomography, Springer, 1-23, 1987.

Paige, C. C. and Saunders, M. A.: LSQR: An algorithm for sparse linear equations and sparse least squares, ACM T. Math. Software, 8, 43-71, 1982.

Park, Y., Nyblade A. A., Rodgers, A. J., and Al Amri, A.: S wave velocity structure of the Arabian Shield upper mantle from Rayleigh wave tomography, Geochem. Geophy. Geosy., 9, Q07020, doi:10.1029/2007GC001895, 2008.
Petrunin, A. G. and Sobolev, S. V.: Three-dimensional numerical models of the evolution of pull-apart basins, Phys. Earth Planet. In., 171, 387-399, doi:10.1016/j.pepi.2008.08.017, 2008.

Petrunin, A. G., Meneses Rioseco, E., Sobolev, S. V., and Weber, M.: Thermomechanical model reconciles contradictory geophysical observations at the Dead Sea Basin, Geochem. Geophy. Geosy., 13, Q04011, doi:10.1029/2011GC003929, 2012.

Ritter, O., Ryberg, T., Weckmann, U., Hoffmann-Rothe, A., Abueladas, A., Garfunkel, Z., and DESERT Research Group: Geophysical images of the Dead Sea Transform in Jordan reveal an impermeable barrier for fluid flow, Geophys. Res. Lett., 30, 1741, doi:10.1029/2003GL017541, 2003.

Rudnick, R. L. and Fountain, D. M.: Nature and composition of the continental crust: a lower crustal perspective, Rev. Geophys., 33, 267-309, 1995.

Smit, J., Brun, J.-P., Cloetingh, S., and Ben-Avraham, Z.: The riftlike structure and asymmetry of the Dead Sea Fault, Earth Planet. Sc. Lett., 290, 74-82, doi:10.1016/j.eps1.2009.11.060, 2010.

Smith, D. E., Kolenkiewicz, R., Robbins, J. W., Dunn, P. J., and Torrence, M. H.: Horizontal crustal motion in the central and eastern Mediterranean inferred from satellite laser ranging measurements, Geophys. Res. Lett., 21, 1979-1982, 1994.

Ten Brink, U. S., Ben-Avraham, Z., Bell, R. E., Hassouneh, M., Coleman, D. F., Andreasen, G., and Coakley, B.: Structure of the Dead Sea pull-apart basin from gravity analyses, J. Geophys. Res.-Sol. Ea., 98, 21877-21894, 1993.

Um, J. and Thurber, C. H.: A fast algorithm for two-point seismic ray tracing, B. Seismol. Soc. Am., 77, 972-986, 1987.

Wdowinski, S., Bock, Y., Baer, G., Prawirodirdjo, L., Bechor, N., Naaman, S., Knafo, R., Forrai, Y., and Melzer, Y.: GPS measurements of current crustal movements along the Dead Sea Fault, J. Geophys. Res., 109, B05403, doi:10.1029/2003JB002640, 2004.

Weber, M., Abu-Ayyash, K., Abueladas, A., Agnon, A., Tasarova, Z., Al-Zubi, H., Babeyko, A., Bartov, Y., Bauer, K., Becken, M., Bedrosian, P. A., Ben-Avraham, Z., Bock, G., Bohnhoff, M., Bribach, J., Dulski, P., Ebbing, J., El-Kelani, R., Forster, A., Forster, H.J., Frieslander, U., Garfunkel, Z., Goetze, H. J., Haak, H., Haberland, C., Hassouneh, M., Helwig, S., Hofstetter, A., Hoffmann-Rothe, A., Jaeckel, K.H., Janssen, C., Jaser, D., Kesten, D., Khatib, M., Kind, R., Koch, O., Koulakov, I., Laske, G., Maercklin, N., Masarweh, R., Masri, A., Matar, A., Mechie, J., Meqbel, N., Plessen, B., Moeller, P., Mohsen, A., Oberhansli, R., Oreshin, S., Petrunin, A., Qabbani, I., Rabba, I., Ritter, O., Romer, R., Rumpker, G., Rybakov, M., Ryberg, T., Saul, J., Scherbaum, F., Schmidt, S., Schulze, A., Sobolev, S.V., Stiller, M., Stromeyer, D., Tarawneh, K., Trela, C., Weckmann, U., Wetzel, H.-U., and Wylegaala, K.: Anatomy of the Dead Sea Transform from lithospheric to microscopic scale, Rev. Geophys., 47, RG2002, doi:10.1029/2008RG000264, 2009. 